\title{
INFECTIVE RETICULO-ENDOTHELIOSIS CHIEFLY LOCALIZED IN LUNGS, BONE MARROW AND THYMUS
}

\author{
BY
}

S. VAN CREVELD, M.D., AND F. H. TER POORTEN, M.D.

(From the Propaedeutic Clinic and the Pathological Laboratory, University of Amsterdam.)

Recently a number of articles have been published on a morbid condition observed especially in young children, in which after death proliferation of the reticulo-endothelial system has been found. This proliferation affected not only the reticulo-endothelium as such, but also groups of cells, such as the histiocytes of Aschoff and the Kupffer cells, which may be looked upon as belonging to this system because they show some of its most prominent characteristics, e.g. phagocytosis and ability to store substances. Depending upon whether it is considered that such proliferation arises in the reticuloendothelium, or in the mesenchymatous cells in connective tissue and round the blood vessels, the morbid process is known variously as reticulosis, reticulo-endotheliosis and histiocytosis.

Of the reticulo-endotheliosis group, which histologically may show great variety in localization as well as in intensity, some sub-groups have already been separated: a. those where a known aetiological factor can be affirmed (tuberculosis, typhoid); and b. those which show characteristic localization and where the proliferated cells have accumulated easily recognized substances. This is the case in the lipoidoses showing a deposit of kerasine in Gaucher's disease, of phosphatides in the disease of Niemann-Pick, of cholesterol and cholesterol-esters in the xanthomatoses. Of the xanthomatoses one has been set apart, namely, the disease of Schüller-Christian, which is caused by the localization of the deposits in the skull and pituitary and characterized by membranous defects in the skull (map-skull), with or without exophthalmus and diabetes insipidus. It may be questioned as to how far a sharp separation of the lipoidoses, especially xanthomatosis, from other proliferations of the reticulo-endothelial system is fully justified, in view of the fact that the deposit of cholesterol and cholesterol-esters with the appearance of typical so-called foam-cells may disappear at a certain stage of the disease $\mathrm{e}^{1,2}$, whereas in other types of reticulo-endothelial proliferation they may appear secondarily.

Putting aside the two groups mentioned above, there still remain a number of cases the classification of which gives rise to difficulty. The clinical picture as well as the localization of the histological changes differ. This point will be discussed later, after the description of the patient under our observation, whose malady, in our opinion, belongs to this group of reticulo-endothelioses. 
Case record.

A girl of four-and-a-half months was admitted to the Infants Department of the Propaedeutic Clinic on May 3, 1934. She was the tenth child of healthy parents; the other children were all well. The child was born normally at term and during the first months of life was well, except for a purulent discharge from the right ear from the fourth week of life. The otitis still existed when the child came into the hospital. The patient was brought because ten days before the mother had noticed that the right arm was moved with pain and difficulty. Four days later she observed the same symptoms in the right leg. The child was not ill, had no elevation of temperature and did not vomit. At first an injury was thought to be the cause of the condition, but later the possibility of poliomyelitis was considered. A skiagram of the right arm however revealed a cystic process in the proximal part of the right humerus. At this stage the infant was admitted to the department. The child was quiet, except for a slight cough. The skull was slightly bossed; the anterior fontanelle had a diameter of about half an inch. Just above the left parietal prominence there was a small soft area with thickened borders. The face was swollen. The eyes showed no abnormality, there was no exophthalmus and the sclerae were normal. The mucous membranes of mouth and throat were pale. In the neck on both sides some small lymph nodes were palpable. There was a slight rachitic rosary; on the chest-wall were some small furuncles. The liver edge was felt one finger-breadth below the costal margin; the spleen was just palpable. The right arm and leg were not quite so freely movable as the left but there was no tenderness. The reflexes were normal. In axillae and groins some small glands could be felt and in the lower middle part of the back a few small nodules were palpable, situated probably in the subcutaneous tissue. Over both lungs many coarse bronchitic râles could be heard. The von Pirquet and Mantoux tests were negative. The urine was normal, there being no Bence-Jones proteose or microscopical abnormality. The Wassermann reaction was negative. The calcium-content of the serum was normal, the inorganic phosphate-content of the blood was not increased, non-protein nitrogen was normal, and the cholesterol content of the blood was slightly increased (227 mgm. per cent.). The blood sugar content fasting was normal; a blood sugar curve after ingestion of glucose was prolonged without an abnormal rise. Bacteriological examination of stools and urine was negative. The results of the blood counts on different dates are summarized in table 1. From this table it appears that in the beginning there was a

TABLE 1.-BLOOD PICTURE ON DIFFERENT DATES.

\begin{tabular}{|c|c|c|c|c|c|c|c|c|c|c|c|c|}
\hline \multirow[b]{2}{*}{ Date } & \multirow[b]{2}{*}{$\begin{array}{c}\text { Haemo. } \\
\text { goblin } \\
\text { (Sahli) } \\
\text { per cent. }\end{array}$} & \multirow[b]{2}{*}{$\begin{array}{l}\text { Red cells } \\
\text { per c. mm. }\end{array}$} & \multirow[b]{2}{*}{$\begin{array}{l}\text { White cells } \\
\text { per c. mm. }\end{array}$} & \multirow[b]{2}{*}{$\begin{array}{l}\text { Platelets } \\
\text { (Fonio) } \\
\text { per c.mm. }\end{array}$} & \multicolumn{8}{|c|}{ Differential leucocyte count per cent. of white cells. } \\
\hline & & & & & \begin{tabular}{l}
3 \\
\multirow{3}{*}{} \\
0 \\
0 \\
0 \\
$\frac{0}{2}$
\end{tabular} & 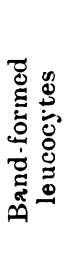 & 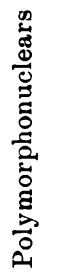 & 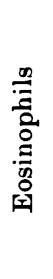 & 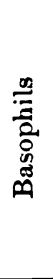 & 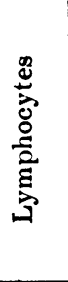 & 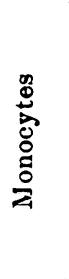 & 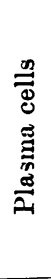 \\
\hline 29.IV.34 & 58 & $4,600,000$ & 10,200 & - & - & $2 \frac{1}{2}$ & $49 \frac{1}{2}$ & - & - & $36 \frac{1}{2}$ & $11 \frac{1}{2}$ & - \\
\hline 4.V. $\ldots$ & 73 & $5,200,000$ & 10,600 & $\begin{array}{l}\text { not } \\
\text { decreased }\end{array}$ & $\frac{1}{2}$ & $5 \frac{1}{2}$ & 51 & 3 & - & 32 & 8 & - \\
\hline 15. V. $\ldots$ & 68 & $4,720,000$ & 11,100 & 377,600 & - & $8 \frac{1}{2}$ & $40 \frac{1}{2}$ & - & - & $42 \frac{1}{2}$ & 7 & $1 \frac{1}{2}$ \\
\hline 17.VI. ... & 57 & $4,740,100$ & 8,200 & - & $\frac{1}{2}$ & $6 \frac{1}{2}$ & 31 & $\frac{1}{2}$ & $\frac{1}{2}$ & 58 & 3 & - \\
\hline
\end{tabular}


slight leucocytosis with a moderate monocytosis; there was no definite anaemia. The temperature during the first weeks was not raised. A detailed $\mathrm{x}$-ray investigation of the skeleton showed that in addition to the cystic condition in the proximal part of the humerus (fig. 1) there existed some membranous defects in the skull (fig. 2). A control skiagram demonstrated

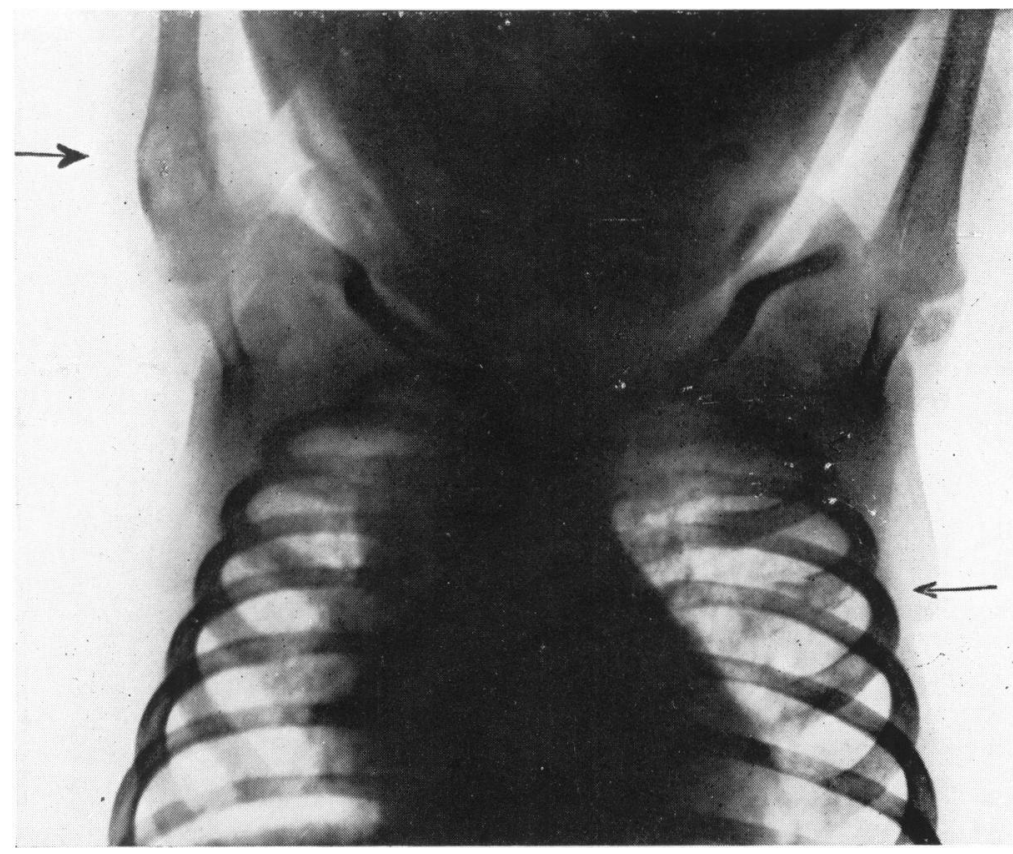

Fic. 1.-Cystic focus in the proximal part of the right humerus and in the left third rib.

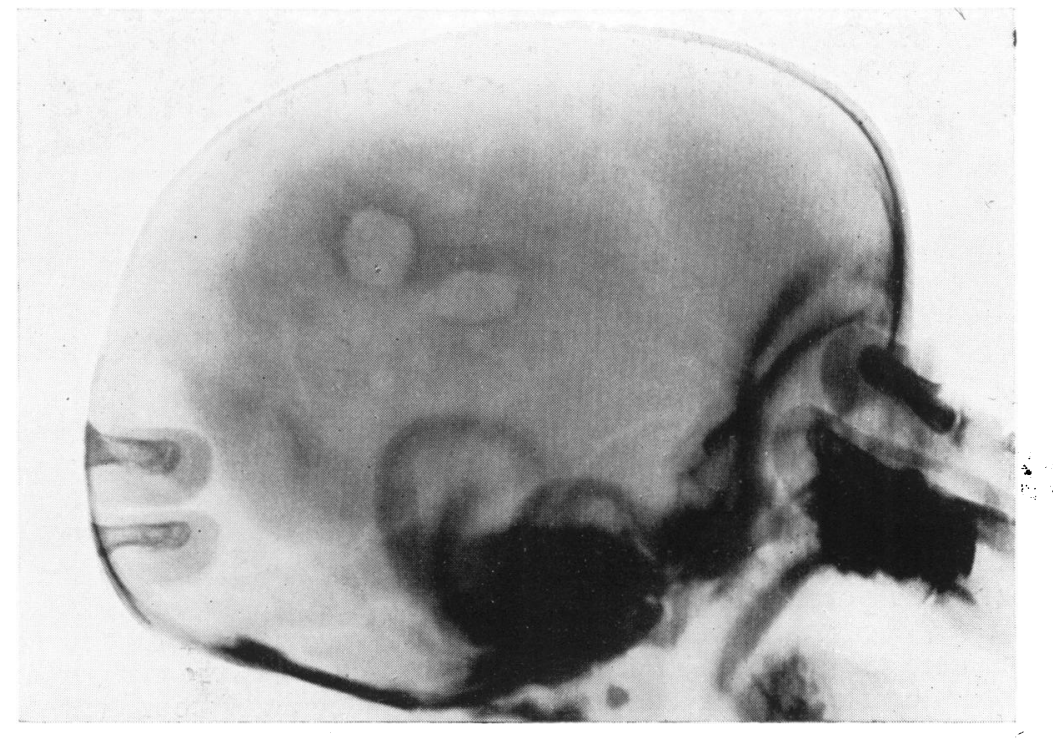

FIc. 2.-Membranous defects in the skull (condition on 4.V.1934). 
that one of these defects corresponded with the palpable defect. It further appeared that there was a cystic rarefaction in the left third rib (fig. 1) and some in the distal part of the right femur (fig. 3) and the left tibia. The $\mathrm{x}$-ray of the lungs showed slight consolidation at the hila and a few opacities in both lungs. The sella turcica was normal.

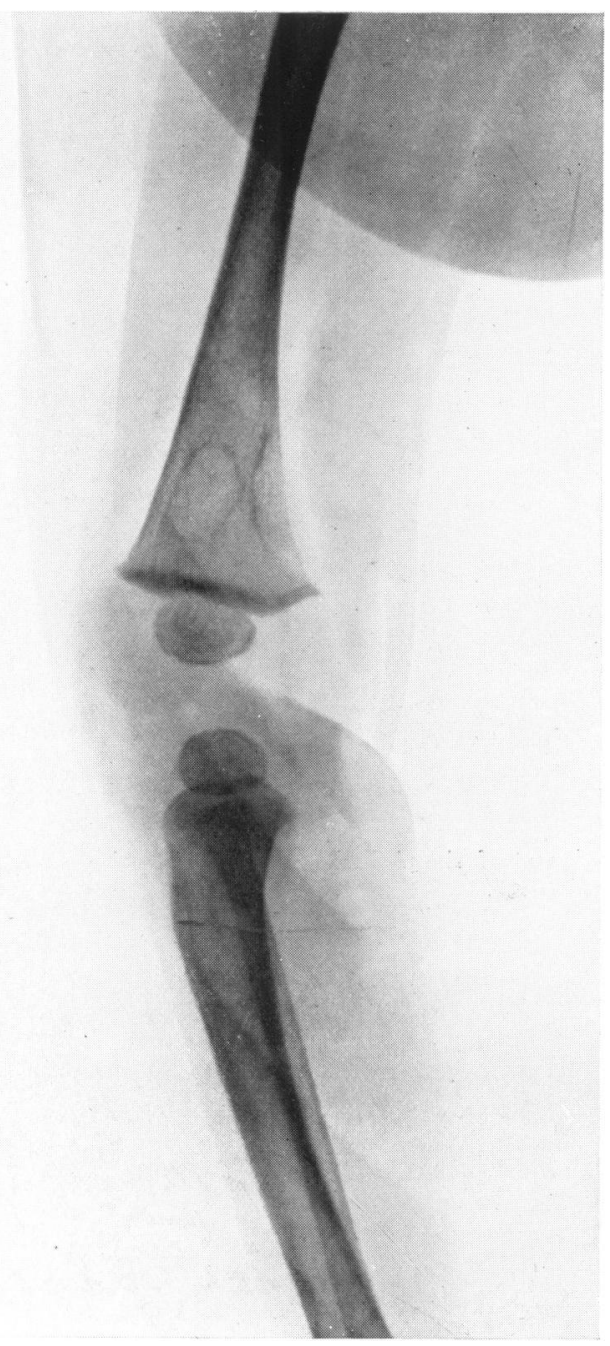

FIf. 3. - Cystic foci in the distal part of the right femur.

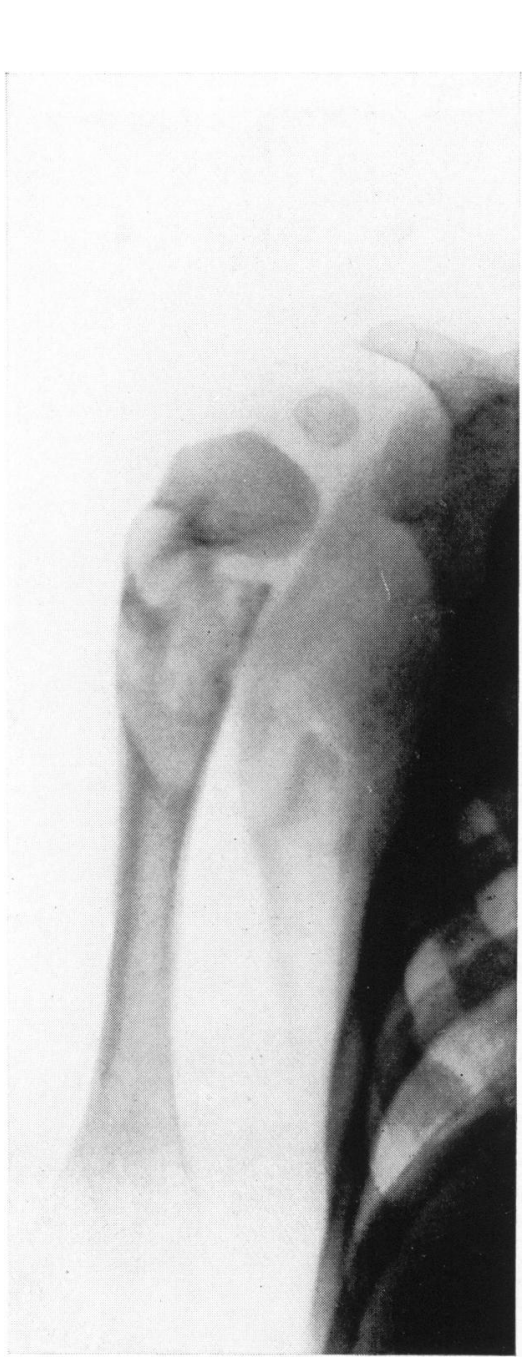

Fic. 4. - Extension of the focus in the right humerus.

During the stay in the hospital the discharge from both ears varied; on two occasions paracentesis of both drums had to be performed. A swelling of the right cheek was noticed for some days. Behind both ears some small nodules were palpable; whether or no they were fixed to the underlying bone remained uncertain. The body temperature was almost constantly raised after the first two weeks. 
While under obervation the number of areas of softening in the skull increased, but still more did the number of defects visible in the skiagram of the skull; a real map-skull developed. The defect in the humerus enlarged and the cortex of the bone was much more involved (fig. 4). At a later stage active and passive movements of the arms and legs appeared to be fairly normal. The skiagram of the lungs showed more abnormalities; dyspnoea increased, but on auscultation only coarse râles could be heard. The bodily condition remained normal, the face became somewhat swollen (fig. 5), the spleen and liver, especially the liver, felt larger.

On May 18 the nodule palpable behind the left ear was aspirated. Some giant cells and some epitheloid cells were found (fig. 6), but no tubercle bacilli were seen. Certainty about the diagnosis could not be obtained in this way. This will be referred to later.

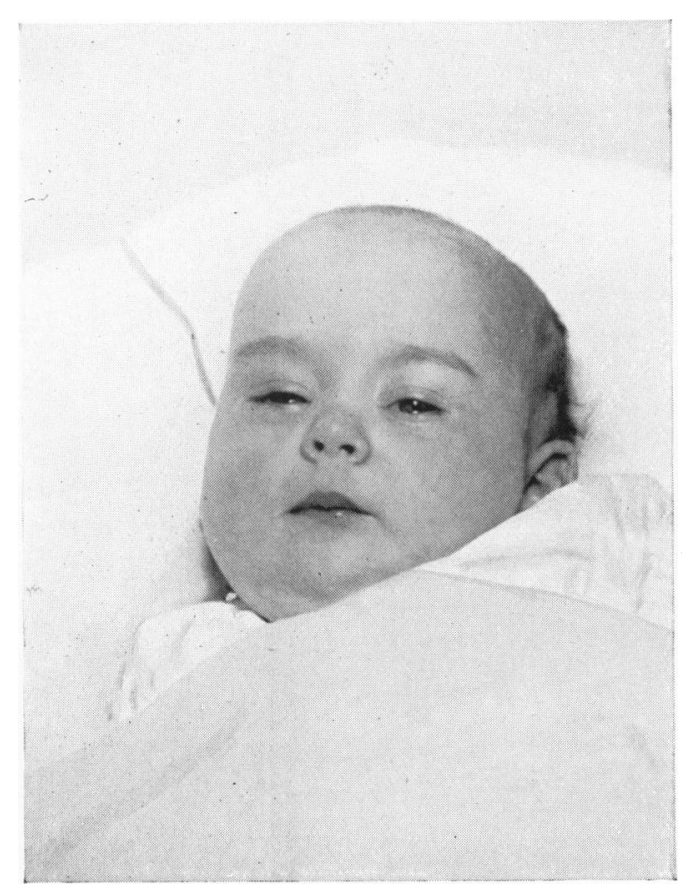

Fr: ; - Photograph of child (16.V.1934).

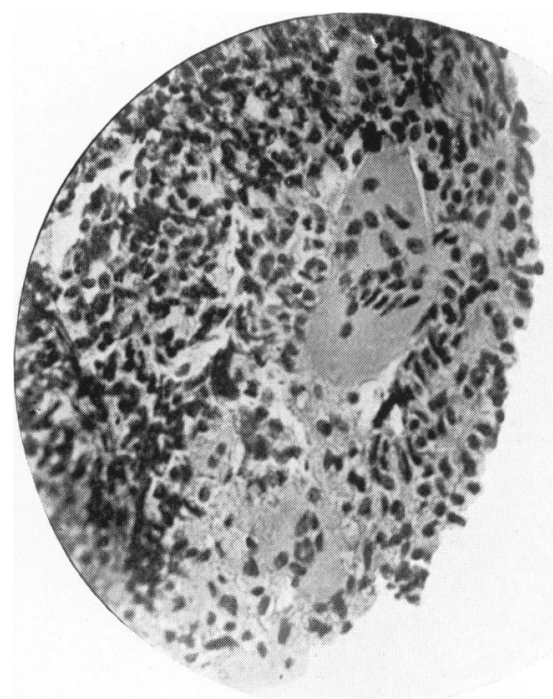

Fili. 6.-Giant cells and epitheloid cells in the punctureHluid from a nodule behind the ear.

The nodules in the back provided a further possible clue to the diagnosis. They could be felt about six $\mathrm{cm}$. above the anal cleft. At the end of May they had slightly increased in size, were probably three in number, of fairly firm consistency, lying under the skin but attached to it. One of the nodules was removed under local anaesthesia; microscopical investigation showed that this was of the nature of an adiponecrosis subcutanea neonatorum ${ }^{3}$. The relation of the fat-necrosis to the rest of the clinical picture, especially to the bone-defects, remained obscure to us.

On June 17 the general condition was still the same, temperature high, colour pale although the haemoglobin content was still 57 per cent. A skiagram of the lungs, on June 14, had shown that on both sides there were many small bronchopneumonic infiltrations and particularly the picture of 
the right lung seemed to point to the formation of small cavities (honeycombstructure). On June 18 the child died suddenly. Two-and-a-half hours after death the thorax and skull were again x-rayed; in the right side of the thorax a pneumothorax was visible (fig. 7), and the skiagram of the skull showed that the number of defects had increased considerably (fig. 8).

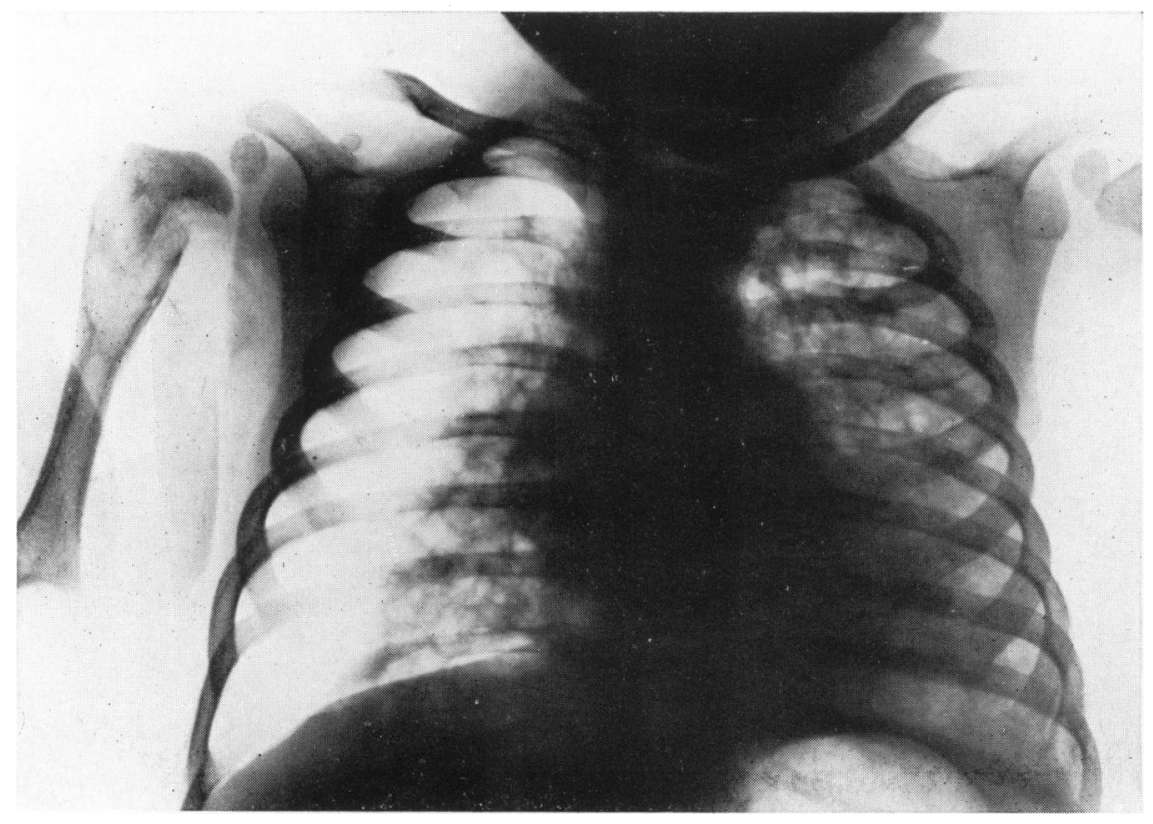

Frg. 7. - Pneumothorax in the right side of the thorax. Honeycomb structure of lungs well marked. The cortex of right humerus is still more involved.

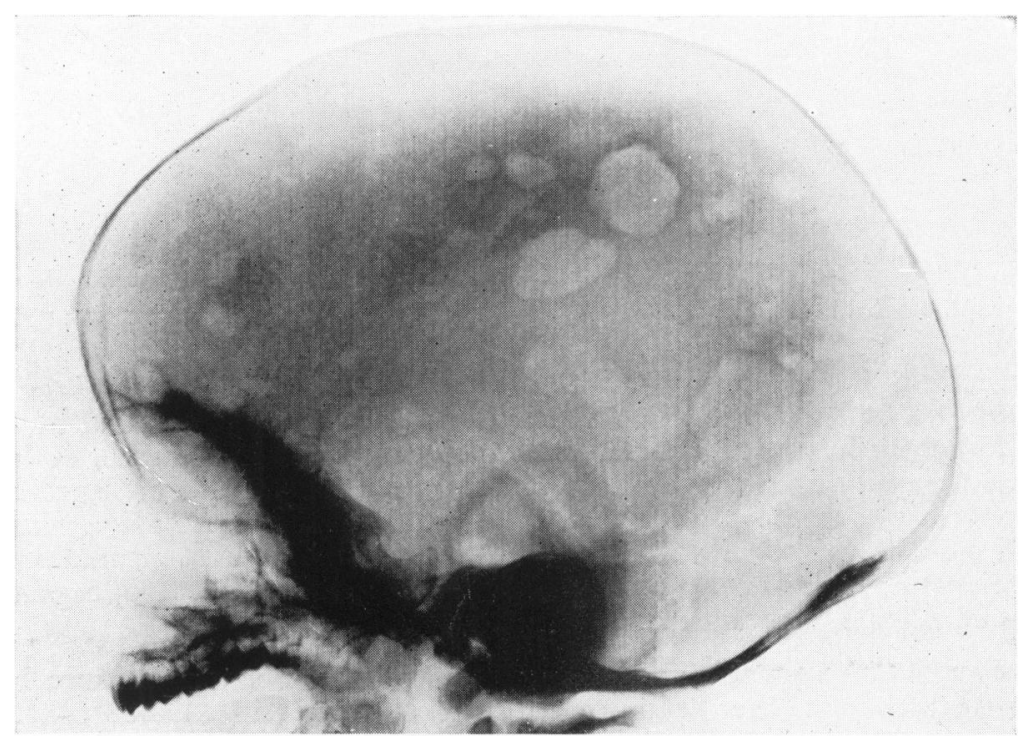

Fig. 8.-Increase of the number of defects in the skull (map-skull) (18. VI.1934). 
As regards the bacteriological investigation, in the fasting stomach content no tubercle bacilli were found, the guinea-pig tests with this fluid remained negative, as well as blood culture, and so also did a further bacteriological investigation of stools and urine. The cholesterol content of the blood two days before death had increased to $596 \mathrm{mgm}$. per cent. with a normal relation between free cholesterol and cholesterol-esters; the lecithin content of the blood was normal, but lowered with regard to the cholesterol.

Short summary of the clinical data.-Otitis media purulenta duplex, osteitis cystica generalisata with map-skull, rickets, micro-polyadenia, hepatomegaly, splenomegaly, broncho-pneumonia, bronchiectasis (?), adiponecrosis subcutanea neonatorum and pneumothorax as cause of death.

\section{Differential diagnosis.}

In order to explain the most prominent features, the multiple bone defects, the following possibilities have to be considered.

1. Osteitis fibrosa generalisata. This disease was regarded as improbable in view of the normal calcium-content of the serum, the absence of a palpable parathyroid tumour, the simultaneous existence of a visceral affection, and the different appearance of the bone defects, especially of those in the skull. Further, osteitis fibrosa is a rare disease in childhood.

2. A malignant tumour (sarcoma metastases or perhaps metastases of a neuroblastoma, or perhaps chloroma). The good general condition until death, the absence of orbital metastases and of any indication of the existence of a malignant tumour obtained in the investigation of the aspirated nodule, were the principal arguments against this possibility.

3. Osteitis tUberculosa CYSTICA with visceral tuberculosis. In itself osteitis tuberculosis cystica is a rare affection; multiple defects in the skull have been described in it, usually associated with cold abscesses in the skull over the defects. The abscesses were absent here and there was no evidence of tuberculous infection.

4. Myelomatosis. Bence-Jones proteose was absent from the urine. In the rare cases of myelomatosis observed at this age, the x-ray appearance, especially of the skull, was different from that in our patient, and the disease progressed here too rapidly for this condition.

5. Xanthomatosis generalisata. In this patient there might be xanthomatosis ossium generalisata as well with visceral xanthomatosis. The combination of the affected organs, the beginning of the disease after a purulent otitis media has also been abserved in other cases; the good general condition, the steady increase in the cholesterol-content of the blood all seemed to be in favour of the diagnosis of xanthomatosis. There have been described in the literature cases of that particular form of xanthomatosis which bears the name of Schüller-Christian's disease in which of the wellknown triad of symptoms only one or two were present ${ }^{4}$. With the varying 
localization of the process this can easily be understood. As regards the rapid extension of the membranous defects in the skull in the present case, this in itself did not exclude the diagnosis of xanthomatosis for rapid extension as well as rapid disappearance are observed in this disease. The fact that no foam-cells were found on aspiration also was no absolute argument against the diagnosis of xanthomatosis. The possibility existed that this was one of those cases, reported recently, in which foam-cells, present at the beginning, had disappeared at a later stage or in which the deposit of cholesterol and cholesterol-esters had not become generalized. In view of all these facts it appeared that this was a case of xanthomatosis generalisata.

To correspond with this diagnosis it was expected to find at autopsy a macroscopical and microscopical picture which is regarded as being typical of generalized xanthomatosis, i.e., an extensive hyperplasia of part of the reticulo-endothelial system in the bone marrow, liver, spleen, lymph nodes, perhaps also in the lungs, with accumulation of cholesterol and cholesterolesters (Rowland"). As regards the lung condition which had given rise to a pneumothorax, it might either be due to xanthomatosis of the lungs, or with a process independent of xanthomatosis and related to cavity formation.

\section{Autopsy report.}

The body was that of a normally-built infant, $67 \mathrm{~cm}$. in length, weight $6.5 \mathrm{kgm}$., fairly well-nourished. In the vertex of the skull several soft areas were felt, some of which had a diameter of more than $1 \mathrm{~cm}$. Signs of mild rickets were present.

A pneumothorax was present on the right side with slight fibrinous pleurisy. The lungs on the surface as well as on the cut surface (fig. 9 (a) and (b)) were crowded with greyish-yellow opaque nodules, which when larger than $1 \mathrm{~mm}$. show a central cavity. These cavities sometimes were as large as a pea but even then their wall was formed by a small layer of the same firm greyish-yellow mass, and not by the lung tissue as in alveolar emphysema. Repeatedly an open communication was seen between the cavities and a bronchus.

The pneumothorax appeared to have been caused by the bursting of two of these vesicles at the base of the right lung.

In the position of the thymus there was a mass of firm consistency, $5.5 \mathrm{~cm}$. in length, $2.5 \mathrm{~cm}$. broad and $3 \mathrm{~cm}$. thick, of which the rather smooth anterior surface was connected with the front wall of the thorax by loose connective tissue. The rest of this mass was adherent to trachea, pericardium and lungs, especially on the right side. The cut surface of this mass had an appearance that did not at all resemble the thymus or lymph nodes. It was a somewhat granular, brittle, cut surface, faint greyish-yellow, with several irregularly formed, opaque yellow spots and some small slightly sunken fibrous stripes, which gave the whole mass a lobular marking. The trachea and bronchi were not narrowed.

There was no pericardial effusion and the heart was normal.

The lymph nodes were all soft and swollen. In the right axilla some nodes showed on section a single greyish-yellow spot of the same appearance as the lung nodules; all other lymph nodes were greyish-pink and free from tuberculosis. The lymphoid tissue of the intestine was slightly swollen, but not ulcerated. The spleen was soft and weighed $45 \mathrm{gm}$. In the liver $(320 \mathrm{gm}$.) there were some greyish-yellow nodules, at most $1.5 \mathrm{~mm}$. large. 
The other organs of neck, thorax and abdomen were normal. Examination of the skull was not allowed.

In the bone marrow of the sternum there were greyish-yellow areas which did not otherwise differ distinctly in structure and consistency from the surrounding red bone marrow. In the upper part of the right humerus the bone marrow was changed from $1 \mathrm{~cm}$. below the epiphyseal line for a length of $2.5 \mathrm{~cm}$. into a somewhat soft, brittle, opaque greyish-yellow mass, in which were several rather more yellow areas. This mass was sharply
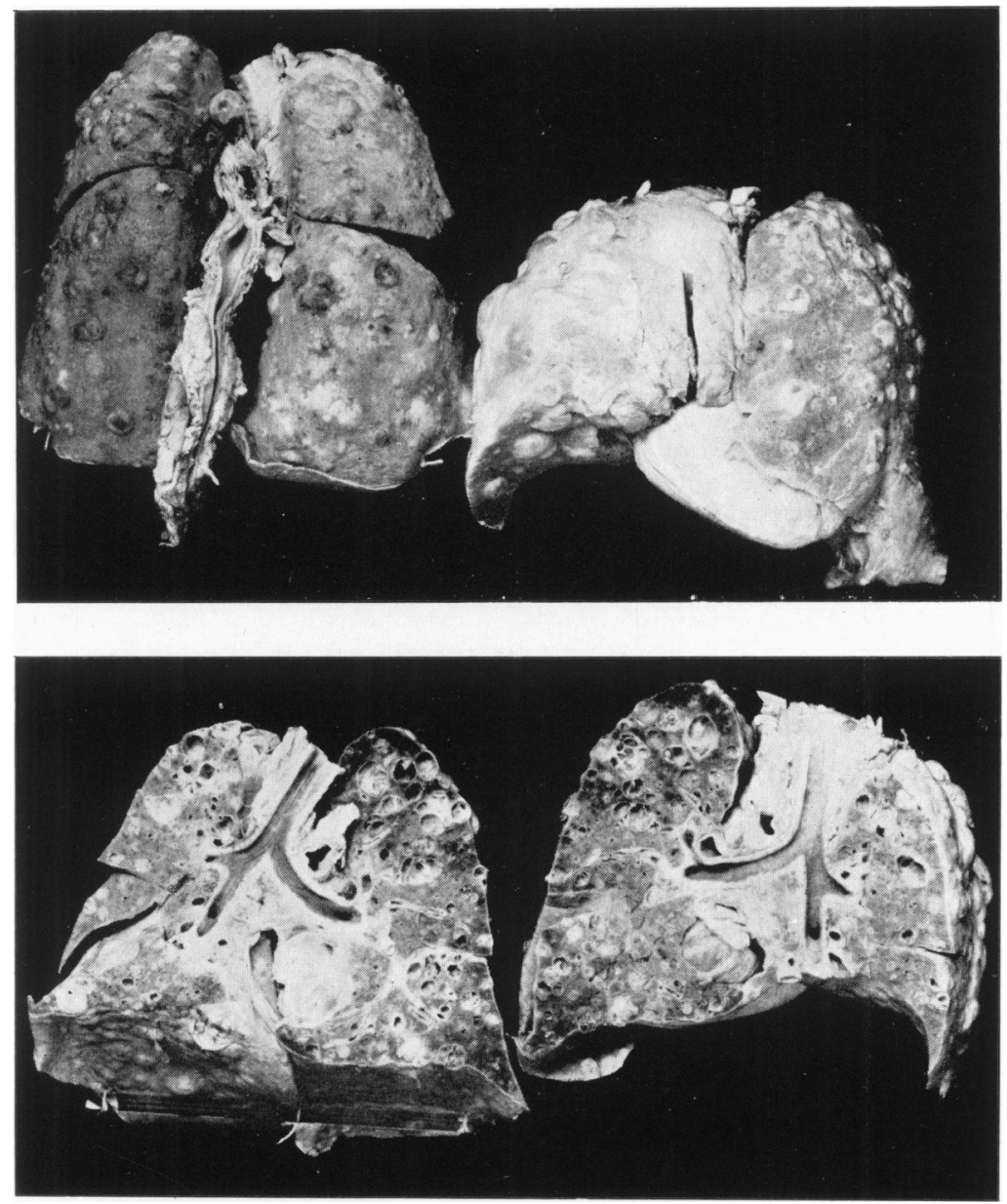

Fic. :. - $(a$ and b). Surface and cut surface of the lungs.

defined from the red bone marrow and, over it, the cortex was irregularly thinned and bent outwards. In the anterior end of the left third rib the bone marrow was altered for a length of several $\mathrm{cm}$. into a light grey or light yellow, soft, often mucous mass, which here and there was directly adjacent to the periosteum.

The autopsy findings were not easy to interpret satisfactorily. The nodular character of the affection resembled tuberculosis, but there was no evidence of a primary lung or intestinal focus. On the other hand, the general impression was that the thymus formed the centre of the pathological 
process, so that the possibility of a malignant tumour of thymus or mediastinal lymph nodes with visible metastases in lungs, lymph nodes, bone marrow and liver was considered. The histological examination brought the solution of the problem.

Microscopic examination. Thymus. Of the thymus tissue only little was left. Only cells with a large amount of protoplasm were seen and this was poorly stained by eosin, so-called pale cells, one to ten times as large as a leucocyte, with one or more nuclei, which in size and structure resembled the endothelial nuclei. The cells were surrounded by fine fibres of reticulum which now and then were thickened to broad waving bundles staining red by van Gieson's method, and everywhere connected to the wall of the oftennumerous vessels. Especially the larger polynuclear cells which seldom resembled the type of Langhans, often showed active phagocytosis (destruction products, lymphocytes, granulocytes, erythrocytes). The tissue which had taken the place of the thymus showed focal necrosis. As remnants of the thymus or of the lymph nodes next to it, were to be seen here and there accumulations of lymphocytes, in the outer layers of which often lay a large number of large pale cells showing phagocytosis. Also as remnants of the thymus tissue were interpreted the rather numerous fields, consisting of necrotic nuclei as large as a lymphocyte, and which are surrounded by a thin layer of flat epithelial-like cells, partly horny without intercellular material. The whole could thus be regarded as a Hassall's corpuscle, cnlarged to ten to twenty times the original size by invasion of necrotizing lymphocytes (fig. 10). They closely resembled Dubois' abscesses.

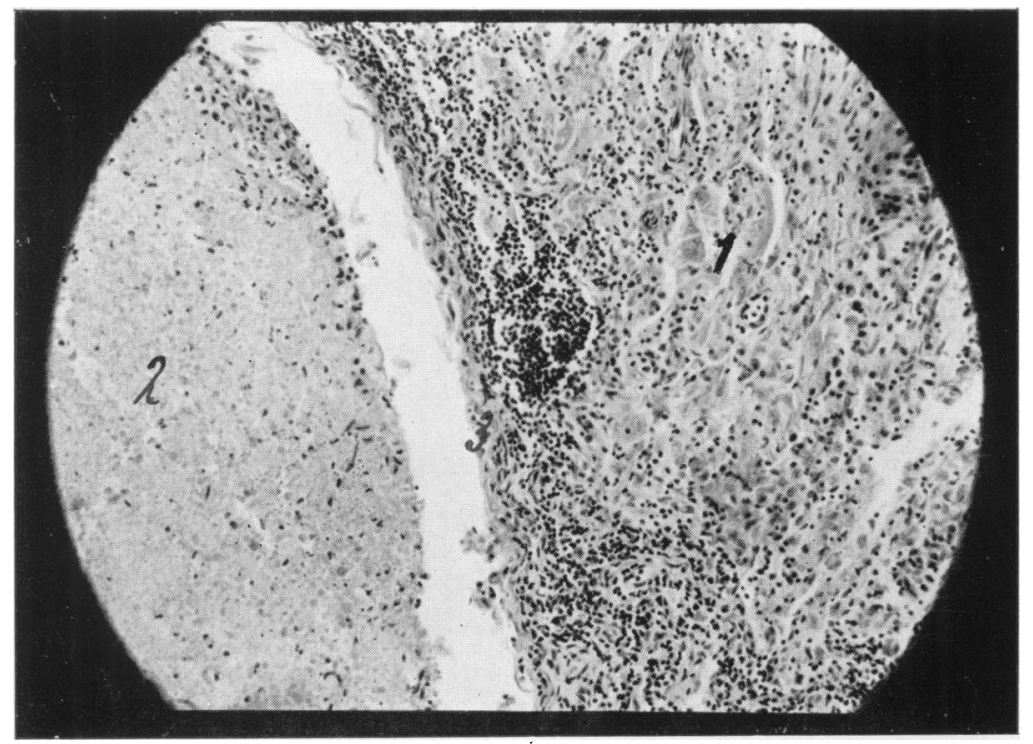

Fic. 10.-Thymus.

1. Proliferated reticular cells (pale cells) among the lymphoid thymus tissue.

2. Necrotic centre of a greatly enlarged Hassall's corpuscle.

3. Exterior horny epithelial layer of a Hassall's scrpuscle.

Lungs. The nodules in the lungs consisted of the same cells as those in the thymus; the smallest were surrounded by a broad infiltrate of lymphocytes. Some nodules were lying in the middle of the lung tissue: the proliferated cells were to be seen in the alveolar septa which had grown 
much broader by this proliferation, whereas the alveoli themselves were coated with a more or less cubical epithelium, such as is seen in chronic pneumonia (fig. 11). Most of the nodules, however, arose from the walls of the vessels and especially of the bronchi (fig. 12), by which process the latter were to a great extent destroyed and partly blocked.

By means of the well-known piston-action it is easy to explain from these findings the formation of the cavities, which macroscopically resembled alveolar emphysema. The new tissue not only showed an inclination to necrosis but also it seemed to be brittle. Microscopically the walls of the cavities were not formed by lung tissue, but by proliferated cells, in which sometimes remnants of bronchial epithelium could be seen.

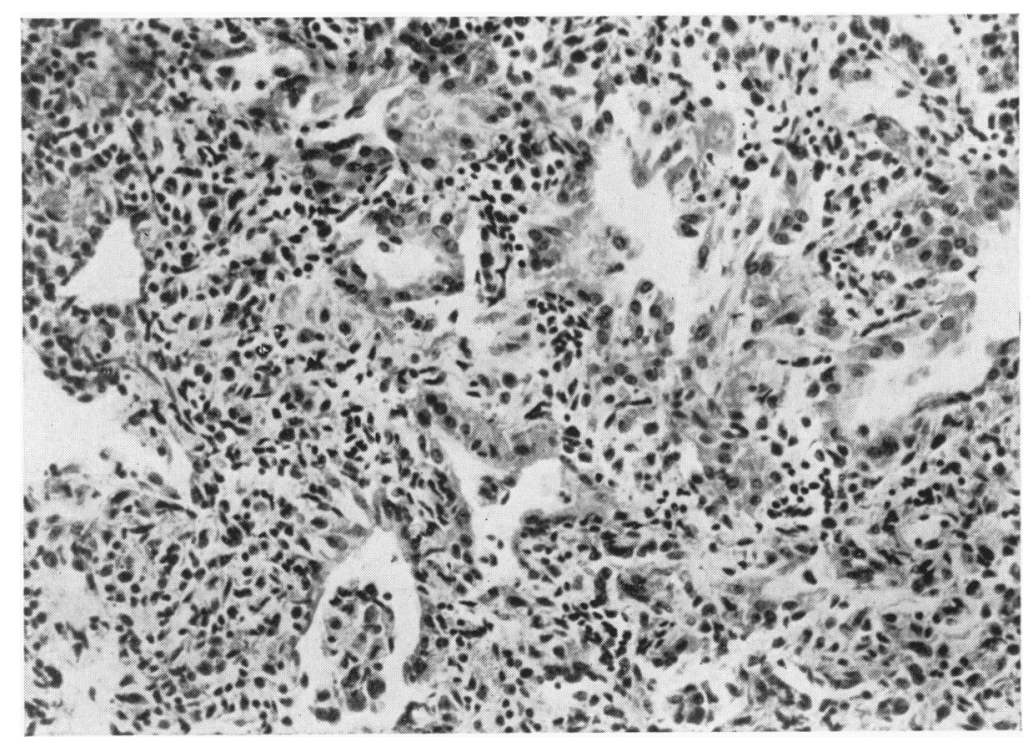

Fig. 11.-Area of cellular proliferation in the middle of the lung tissue. The proliferated cells are found in the broadened alveolar septa. The alveoli are coated with cubical epithelium.

LYMPH NODEs. Everywhere there was so-called ' sinus catarrh.' Furthermore, here and there cellular proliferation at the border or in the centre of the follicles could be seen. In one axillary gland there was a large nodular proliferation in the wall of the outer sinus.

SpleEN. This organ contained a good deal of blood. Spreading cellular proliferation issued either from the walls of the vessels, which they surrounded like a cloak, or of the red pulp, in which case they penetrated the follicles from the periphery (fig. 13).

Liver. There were small areas of cellular proliferations, with extensive infiltration of lymphocytes round the bile ducts. The larger proliferations showed distinct connections with the peri-portal connective tissue.

BONE MARROW (STERNUm). The same cellular proliferation was seen with necrosis, of which the fine thread-like reticulum is connected to the wall of the vessels. Decrease of the myeloid elements was present and also bone destruction. 
Other organs. The thyroid gland, heart muscle, suprarenal glands, kidneys, pancreas, lymphoid tissue of the gastro-intestinal tract, and some voluntary muscles showed no cellular proliferation on microscopic examination.

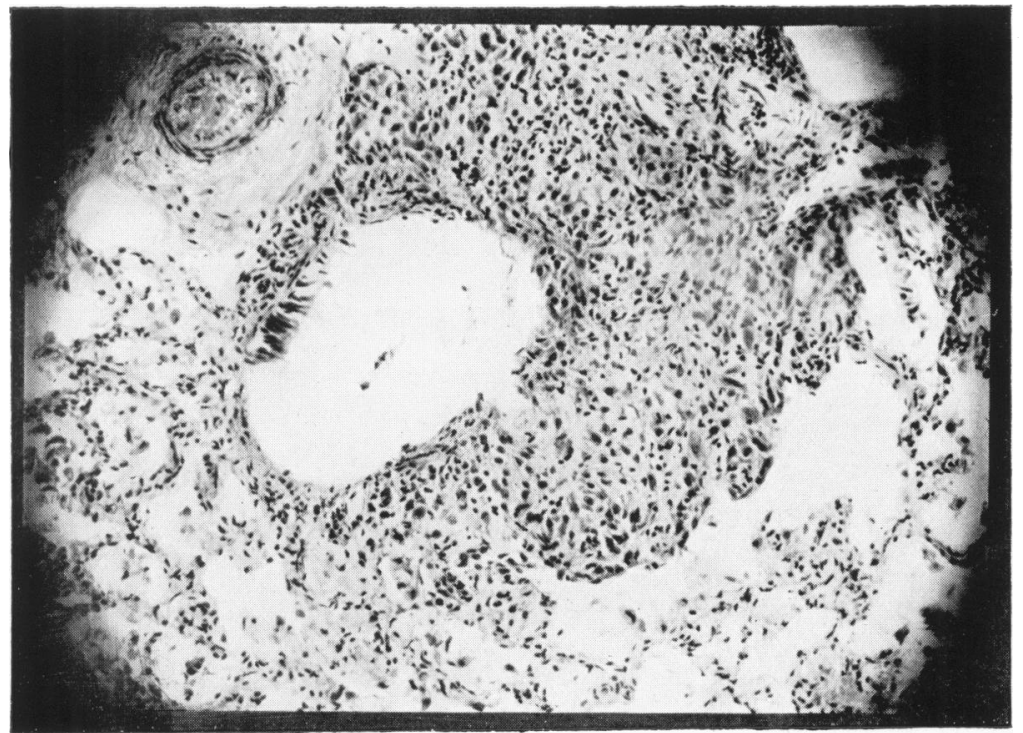

Fic. 12.-Cellular proliferation in the lung issuing from the bronchial wall. The bronchial wall can be recognized by the remains of cylindric epithelium and by its situation next to an artery.

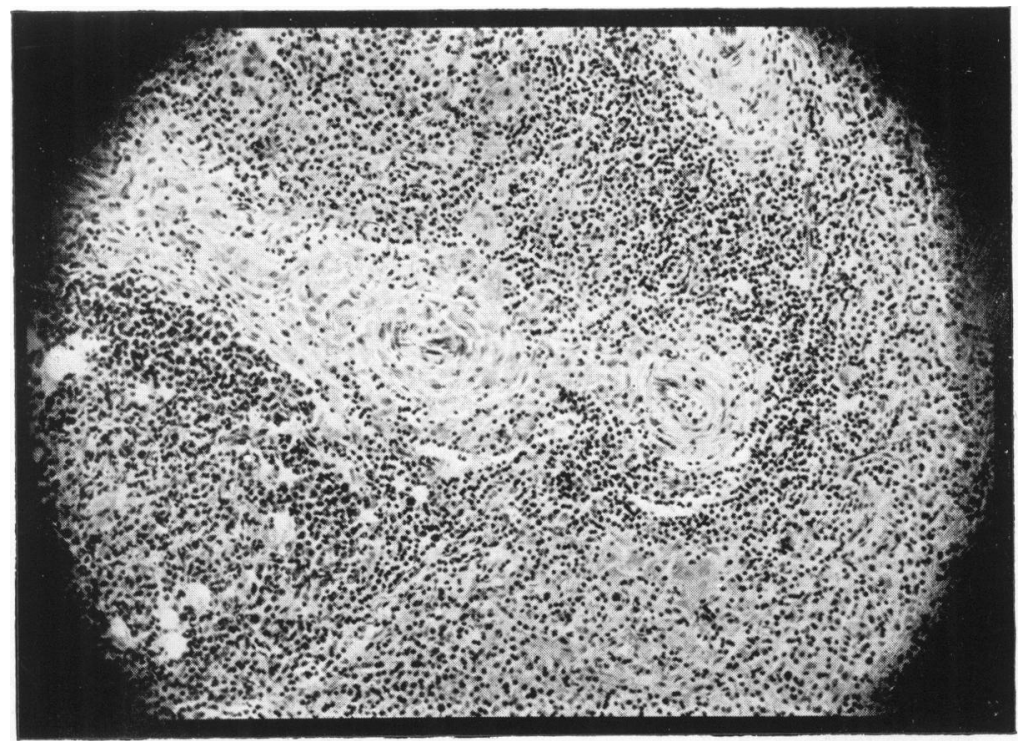

Fig. 13.-Spleen. Peri-adventitial cellular proliferation.

Bacteriological examination for tubercle bacilli, spirochaeta pallida and that of Gram-stained sections was everywhere negative. On histological examination of the proliferated cells accumulations of fat or of lipoids could nowhere be found. 


\section{Discussion of pathological findings.}

The results of the autopsy and of the microscopic examination justify the diagnosis of an unusual localization of an affection which in recent years has been described several times: a so-called reticulo-endotheliosis. The provisional diagnosis made during life was confirmed in so far as a reticuloendotheliosis was indeed found, but not that form which is known as xanthomatosis. Typical foam-cell proliferation was not found in any organ, and certainly not in the bone marrow, and the pathological process showed a character of its own. The bone lesions found during life, as also the mapskull, are however produced in this case by a similar process to that occurring in xanthomatosis ossium, e.g. proliferation of reticulum cells of the bone marrow, giving rise to invasion and destruction of the bone.

From the relation between the pathological pale cells and the pre-existing tissue it may safely be deduced, that these cells originated from a proliferation of cell groups present in different organs, which belong to the reticuloendothelial system. Those cell groups are: in the thymus, the peripheral reticulum formed by the pericytes; in the lungs, the histiocytes in the alveolar septa and in the connective tissue round bronchi and vessels; in the lymph glands, the lymphoid reticulum; in the spleen, the reticulum of the pulp and the peri-adventitial cells; in the bone marrow the myeloid reticulum; in the liver the histiocytes in the peri-portal connective tissue.

Two points need further discussion. First: the necrotic areas found in the thymus, which were surrounded by pavement epithelium and which were regarded as being altered Hassall's corpuscles, have also been observed by others and sometimes have been explained in the same way (Guizetti ${ }^{6}$ Siwe $^{7}$, Letterer ${ }^{8}$, Foot and Olcott ${ }^{18}$ ).

Second: although several writers on reticulo-endotheliosis have also found cellular proliferation in the lungs (Guizetti, Podvinec and Terplan', Siwe, Uher ${ }^{10}$ ), such proliferation nowhere showed such an unusual picture as found in the present case. It is true that Siwe states that the lungs in his case showed a bullous emphysema, but the nature of this emphysema is not clear from the histological description. This different aspect must be explained by the point of issue of the cellular proliferation, in the present case the bronchial wall, in the others the alveolar septa. In the case described by Guizetti the proliferation originated from the interlobular connective tissue, where perhaps surrounding alveoli have been destroyed, this being the cause and explanation of the finding of air in the soft parts of the neck, in the anterior mediastinum, in the connective tissue of the thymus, and under the visceral pleura. 
On the other hand, a picture of the lungs similar to that in the present case has only been described by Apert, Girard and Rappoport ${ }^{11}$, in a boy of seven years. Here this condition resembling the bullous emphysema was caused by a destruction of the bronchial walls due to congenital syphilis.

Finally, the question arises as to whether the results of the pathological examination contain some data which can be used to explain the nature of the reticulo-endothelial proliferation. Although, as said before, the macroscopic examination suggested a tumour, this was disproved by the microscopic examination. The cellular proliferation which in different organs originated from different parts of the reticulo-endothelial system appeared to be a reaction to stimulation, for example of an infection. This conception is supported by the fact that another form of reaction, i.e. an exudative one, was found, showing itself in cellular infiltration in lung and liver, while a widespread 'sinus catarrh' in the lymphatic glands, so often found in generalized infections, also pointed in the same direction. The reticuloendotheliosis described above might thus be considered to be chiefly a proliferative response to an infectious agent.

At the end of the discussion of the pathological appearances, macroscopic and microscopic, of this disease, the question may be put as to how far the clinician may profit by these results with a view to diagnosing it. From the cases described by Siwe and by Foot and Olcote it may be concluded that puncture of the spleen (Siwe) or biopsy of the spleen (Foot and Olcott) may procure important findings indicating the existence of the disease and that certain related diseases can be excluded in this way. In the present case the result of the examination of the puncture of the nodule behind the left ear might have afforded some indication of the diagnosis, as epitheloid cells and giant cells without tubercle bacilli were found. At that time, however, the possibility of an infective reticulo-endotheliosis was not thought of.

\section{General considerations.}

A survey of the cases of reticulo-endotheliosis, published in recent years, which were not caused by a specific infection and did not belong to the lipoidoses-(and this discussion is restricted to the cases observed in childhood*)-shows that the case here reported resembled these in many

*To the cases of reticulo-endotheliosis in childhood mentioned here may be added one described by Borissowa ${ }^{19}$ in 1903 under another title. According to the very exact description of the change found, it is now justifiable to say that the patient, a child of nineteen months, suffered from reticuloendotheliosis with its principal localization in the lymphoid apparatus. Clinical data are missing. Of a case of reticulosis recently observed by Paige in a young child there has only appeared an abstract ${ }^{21}$ so far. 
respects but also showed many differences. In table $\mathbf{2}$ a summary is given of the most important clinical and histological details in cases in the literature. The similarity lies first of all in the age at which the first symptoms are observed. As in Niemann-Pick's disease and in Schüller-Christian's disease

TABLE 2.--SUMMARY OF THE MOST IMPORTANT CLINICAL AND HISTOLOGICAI, FINDINGS IN ANALOGOUS CASES.

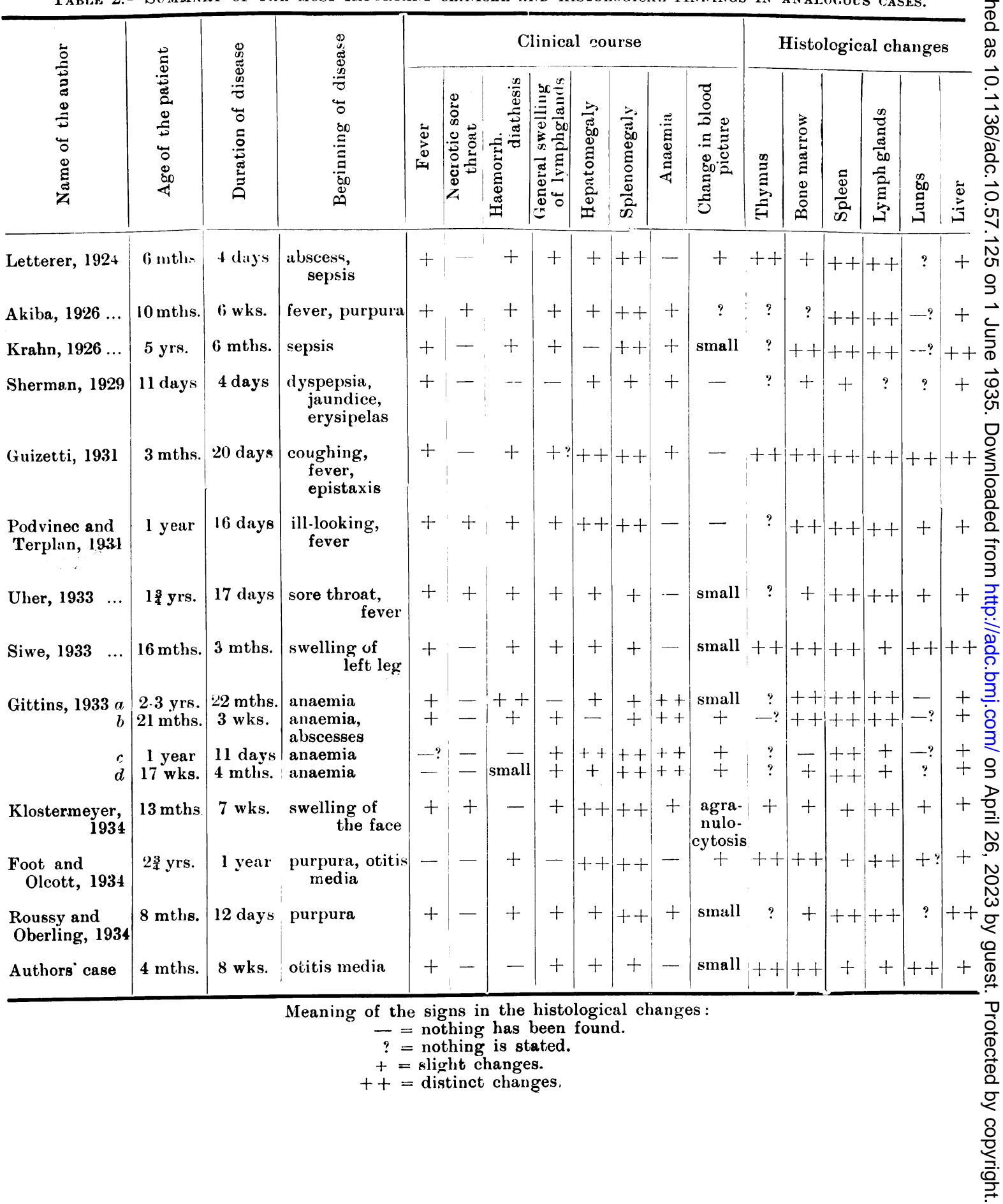


the patients are for the most part young children; so that the impression is again obtained that in young children the reticulo-endothelial system reacts readily to stimulation. A second point of agreement lies in the fact that some form of infection in the aetiology can hardly ever be denied; thus the first symptoms of the disease were often observed following an acute infectious disease. As observed in cases of xanthomatosis in childhood acute otitis media often preceeded the disease (as in the present case) or soon after the beginning of the disease otitis media occurred (Letterer) or this was found at the autopsy after a short course of the disease (Podvinec and Terplan). A necrotic type of sore throat (Akiba ${ }^{12}$, Podvinec and Terplan, Uher, Klostermeyer ${ }^{13}$ ) was often present at the onset. Repeatedly the clinical course pointed to sepsis as a cause of the disease by the presence of fever, enlargement of spleen and lymph nodes, and the presence of a haemorrhagic tendency. The course of the disease is mostly short, often only two to three weeks, but sometimes months or even years. In a case described by Sherman of an infant eleven days old, the disease (dyspepsia, infective jaundice, erysipelas) lasted only four days. At the necropsy no real reticuloendothelial proliferation was found but an enormous swelling and partial necrosis of reticulo-endothelial cells, with intensive phagocytosis of streptococci.

In the present case an infectious basis for the proliferation of the reticuloendothelial system must seriously be considered. The result of the pathological examination supports this conception as already indicated, but the clinical picture is also in favour of this as shown by the otitis media which preceded the disease, the fever which remained throughout the disease although the otitis media diminished in severity, and the slightly infective type of blood picture. The cultural and bacteriological investigations were totally negative. The infective origin of the disease cannot be excluded on this ground, just as this is not absolutely proved by the fact that in other cases at the necropsy accumulations of cocci were found in different organs (Guizetti, Uher), and during life bacteria were cultivated from the blood (Foot and Olcott, Sherman). All these facts make it highly probable that an infection was the cause of the reticulo-endotheliosis in our case. There is no evidence here to point to a primary disturbance of metabolism as is the case in the lipoidoses which are also often associated with bone defects. In this connection too much stress must not be laid on the increase of the cholesterol content of the blood found in the present case shortly before death.

As the disease under discussion so often affects the reticulum of the haemopoietic organs, the results of blood examinations in the different cases published have been studied with great interest. These results reveal no constant feature. In some cases there was the picture of an acute or chronic, regenerative or aplastic anaemia (Gittins ${ }^{14}, \mathrm{Krahn}^{15}$ ). In most cases there was no or only a slight secondary anaemia. As a rule the number of leucocytes was normal or slightly increased. Sometimes there was a distinct leucopenia (Foot and Olcott); rarely there was a definite leucocytosis. The 
white blood picture showed little change. Klostermeyer's case ran the course of an agranulocytosis; sometimes there was a moderate monocytosis or a picture that resembled acute leukaemia.

Finally, mention must be made of the localization of the changes found clinically and at the pathological examination; these localizations differed greatly in the various cases. Mostly the disease affected the lymphoid apparatus, spleen and lymph nodes. This localization, combined with the blood picture, in some cases gave rise to the clinical diagnosis of anaemia pseudo-leukaemia infantum of von Jaksch. In one case (Klostermeyer) the anatomical picture resembled of typhoid fever, though histological and bacteriological investigation did not confirm this. Less frequently and to a lesser extent the reticulo-endothelial system in the liver, lungs and bone marrow was affected. Clinically the spleen and liver enlargement (with a number of accompanying symptoms) may be prominent, which must be remembered in the differential diagnosis of this combination. This was stressed particularly by Siwe. In the cases described by Letterer and recently by Roussy and Oberling ${ }^{20}$, which otherwise ran a similar course, changes in the skin were noticed.

As regards the localization of the process the present case was a most unusual one. Not so much because of the appearance of the lungs, for this could be explained readily by the peculiar localization of the reticuloendothelial proliferation in the lungs, but because of the bone changes; their presence and enormous extension could be observed clinically. In this extension and in this form they have not been observed in analogous cases. Their origin must have a similar explanation as, for example, in xanthomatosis. Guizetti and Siwe also observed changes in the bones in their cases during life, but only in the right humerus and left fibula respectively; in one of his patients Gittins found at the x-ray examination and at the autopsy slight changes in the bones. In the case described by Foot and Olcott the changes in the bones were more extensive; there were lesions in the spine, causing kyphosis, which fact had suggested the diagnosis of Pott's disease; the same has occurred sometimes in xanthomatosis (Anspach). Usually the bone changes are only found at the histological examination. The case of Schultz, Wermbter and Puhl ${ }^{16}$ with skull defects and exophthalmus has not been considered in our study, because doubt has been expressed as to whether this was a pure case of infective reticuloendotheliosis or not; it might either be an example of xanthomatosis in a later stage, or of lymphogranulomatosis.

It is remarkable that the bone changes found in the present case and also in those of Guizetti, Siwe and especially of Foot and Olcott, were associated with an extensive destruction of the thymus tissue caused by the reticulo-endothelial proliferation. Is this a remarkable coincidence, or is there some relation between the intensity of the bone changes, situated often near the epiphyses and in the absence of a hormonal influence which, as is now accepted, is exercised by the thymus in young individuals upon the development of the bones? For the present 
a definite reply to this question cannot be given. The combination of thymic and bony changes is also interesting from another point of view. The thymus in general is rarely diseased, yet it is frequently affected in the rare condition of reticulo-endotheliosis. Perhaps the malady here discussed is a specific infection with a particular affinity for the thymus. In every case it seems desirable that in the clinical and histological examination of similar patients special attention should be paid to the thymus, with a view eventually to a clearer classification of these particular affections. This means that the possibility of the existence of reticulo-endotheliosis with particular localization in the thymus must also be considered in the clinical investigation of young children who show infective symptoms combined with $\mathrm{x}$-ray changes in bone, and in whom there is no reason to accept the existence of a primary disturbance in metabolism.

\section{Summary.}

The clinical picture and the detailed autopsy findings in a child aged four months are described with a diagnosis of reticulo-endotheliosis. The cause of the proliferation of the reticulo-endothelial system is attributed to an infection. Clinically extensive bone changes with development of a map skull were prominent. Pathologically an unusual localization of the process in thymus and lungs was found; in the lungs this had given rise to a very unusual picture. The clinical findings and those found after death are compared with those found in a number of analogous cases published in recent years.

\section{REFERENGES.}

1. Snapper, I., Nederl. tijdschr. v. geneesk., Amsterdam, 1934, LXXVIII, 5601.

2. Anspach, W. E., Am. J. Dis. Child., Chicago, 1934, XLVIII, 348.

3. Carol, W. L. L., \& v. d. Zande, F., Nederl. tijdschr. v. geneesk., Amsterdam, 1925, LXIX, 1317.

4. Henschen, F., Acta paediat., Stockholm, 1932, XII, Supplem. VI, 1, and Pincherle, M., Arch. ital. di pediat. e puericult, Bologna, 1932, I, fasc. 1.

5. Rowland, R. S., Arch. Int. Med., Chicago, 1928, XLII, 5 and 611.

6. Guizetti, H. U., Virchows Arch. f. path. Anat., Berlin, 1931, CCLXXXII, 194.

7. Siwe, St. A., Ztschr. f. Kinderh., Berlin, 1933, LV, 212.

8. Letterer, E., Ztschr. f. Path., Frankfort, 1924, XXX, 377.

9. Podvinec, E., \& Terplan, K., Arch. f. Kinderh., Stuttgart, 1931, XCIII, 40.

10. Uher, V., Virchows Arch. f. path. Anat., Berlin, 1933, CCLXXXIX, 504.

11. Apert, E., Girard, L., \& Rappoport, Bull Soc. de pédiat. de Paris, Paris, 1929, III, 174 .

12. Akiba, R., Virchows Arch. f. path. Anat., Berlin, 1926, CCLX, 262.

13. Klostermeyer, W., Beitr. z. path. Anat. u. z. allg. Path., Jena, 1934, XCIII, 1.

14. Gittins, R., Arch. Dis. Childh., London, 1933, VIII, 367.

15. Krahn, H., Deutsches Arch. f. klin. Med., Leipzig, 1926, CLII, 179.

16. Schultz, A., Wermbter, F., \& Puhl, H., Virchows Arch. f. path. Anat., Berlin, 1924, CCLI, 519.

17. Sherman, I., Arch. Path., Chicago, 1929, VII, 178.

18. Foot, N. Ch., \& Olcott, Ch. F., Am. J. Path., Boston, 1934, X, 81.

19. Borissowa, A., Virchows Arch. f. path. Anat., Berlin, 1903, CLXXII; 108.

20. Roussy, G., \& Oberling, C., Wien. Med. Wchnschr., Vienna, 1934, LXXXIV, 407,

21. Paige, B. H., Am. J. Dis. Child., Chicago, 1935, XLIX, 266, 